\title{
IMPLICAÇÕES DA COVID-19 NUM SERVIÇO \\ DE TRANSPLANTE DE CÉLULAS-TRONCO \\ HEMATOPOÉTICAS REFERÊNCIA NA AMÉRICA LATINA
}

\author{
IMPLICATIONS OF COVID-19 IN A HEMATOPOIETIC \\ STEM CELL TRANSPLANTATION SERVICE \\ REFERENCE IN LATIN AMERICA
}

\section{IMPLICACIONES DEL COVID-19 EN UN SERVICIO DE TRASPLANTE DE CÉLULAS MADRE HEMATOPOYÉTICAS DE REFERENCIA EN AMÉRICA LATINA}

\author{
Natália Naome Oshiro ${ }^{1}$ \\ Luciana de Alcantara Nogueira ${ }^{2}$ \\ Luana Aparecida Alves da Silva ${ }^{3}$ \\ Teresinha Keiko Kojo ${ }^{4}$ \\ Celina Angélica Mattos Machado ${ }^{5}$ \\ Fernanda Rackes da Silva Fagundes ${ }^{6}$ \\ Luciana Puchalski Kalinke
}

Como citar este artigo: Oshiro NN, Nogueira LA, Silva LAA, Kojo TK, Machado CAM, Fagundes FRS, et al. Implicações da Covid-10 num serviço de transplante de células-tronco hematopoéticas referência na América Latina. Rev baiana enferm. 2020;35:e43682

Objetivo: descrever as implicações ocasionadas pela pandemia COVID-19 num serviço de referência para Transplante de Células-Tronco Hematopoéticas na América Latina. Método: estudo observacional, transversal, realizado entre março e outubro de 2020. Foram analisadas descritivamente as mudanças instituídas no serviço de transplante e comparadas com os protocolos de cuidado desenvolvidos por instituições internacionais e nacionais, e o reflexo dessas ações nos atendimentos ambulatoriais, nas internações, nos transplantes e na equipe multiprofissional. Resultados: das 137 internações, 25 (18\%) pacientes apresentaram sintomas respiratórios ou febre, dos quais 2 estavam positivos para SARS-CoV-2. Dos 72 profissionais, 8 (11\%) foram contaminados, sendo 5 assintomáticos. Foram adotados novos fluxos de atendimento com o intuito de minimizar os riscos e a exposição, como o reagendamento de consultas e o adiamento de transplantes. Conclusão: as intervenções realizadas mostraram-se eficientes e estão

\footnotetext{
Enfermeira. Mestre em Saúde Coletiva. Enfermeira da Unidade de Transplante, Oncologia e Hematologia do Complexo Hospitalar de Clínicas. Curitiba, Paraná, Brasil. natoshirokahlo@gmail.com. http://orcid.org/0000-0002-8290-4796.

Enfermeira. Doutora em Enfermagem. Professora do Departamento da Universidade Federal do Paraná. Curitiba, Paraná, Brasil. http://orcid.org.0000-0002-5 985-7418.

3 Enfermeira. Mestre em Enfermagem. Enfermeira da Unidade de Transplante, Oncologia e Hematologia do Complexo Hospitalar de Clínicas. Curitiba, Paraná, Brasil. http://orcid.org/0000-0003-0210-2791.

4 Enfermeira. Chefe de Enfermagem da Unidade de Transplante, Oncologia e Hematologia do Complexo Hospitalar de Clínicas. Curitiba, Paraná, Brasil. http://orcid.org/0000-0002-1939-0630.

5 Enfermeira. Mestre em Enfermagem. Enfermeira da Unidade de Transplante, Oncologia e Hematologia do Complexo Hospitalar de Clínicas. Curitiba, Paraná, Brasil. http://orcid.org/0000-0002-724I-7169.

6 Enfermeira. Enfermeira da Unidade de Transplante, Oncologia e Hematologia do Complexo Hospitalar de Clínicas. Curitiba, Paraná, Brasil. http://orcid.org/00000002-7194-6501.

Enfermeira. Pós-doutora em Ciências da Saúde. Professora do Departamento de Enfermagem da Universidade Federal do Paraná. Curitiba, Paraná, Brasil. http://orcid.org/0000-0003-4868-8193.
} 
de acordo com as recomendações de órgãos nacionais e internacionais, no entanto, a constante vigilância é uma necessidade.

Descritores: Transplante de Células-Tronco Hematopoéticas. Transplante de Medula Óssea. Infecções por Coronavírus. Vírus da SARS. Cuidados de Enfermagem.

Objective: to describe the implications caused by the COVID-19 pandemic in a reference service for Hematopoietic Stem Cell Transplantation in Latin America. Method: observational, cross-sectional study conducted between March and October 2020. The changes instituted in the transplant service were descriptively analyzed and compared with the care protocols developed by international and national institutions, and the reflection of these actions in outpatient care, hospitalizations, transplants and multiprofessional staff. Results: of the 137 hospitalizations, 25 (18\%) patients had respiratory symptoms or fever, of which 2 were positive for SARS-CoV-2. Of the 72 professionals, $8(11 \%)$ were infected, with 5 asymptomatic. New care flows were adopted in order to minimize risks and exposure, such as rescheduling appointments and postponing transplants. Conclusion: the interventions performed were efficient and are in accordance with the recommendations of national and international bodies, however, constant surveillance is a necessity.

Descriptors: Hematopoietic Stem Cell Transplantation. Bone Marrow Transplant. Coronavirus Infections. SARS Virus. Nursing Care.

Objetivo: describir las implicaciones causadas por la pandemia de COVID-19 en un servicio de referencia para el Trasplante de Células Madre Hematopoyéticas en América Latina. Método: estudio observacional transversal realizado entre marzo y octubre de 2020. Los cambios instituidos en el servicio de trasplante fueron analizados descriptivamente y comparados con los protocolos de atención desarrollados por instituciones internacionales $y$ nacionales, $y$ el reflejo de estas acciones en atención ambulatoria, hospitalizaciones, trasplantes y personal multiprofesional. Resultados: de las 137 internaciones, 25 (18\%) pacientes tenían sintomas respiratorios o fiebre, cuyo 2 eran positivos para SARS-CoV-2. De los 72 profesionales, 8 (11\%) estaban infectados, con 5 asintomáticos. Se adoptaron nuevos flujos de atención para minimizar los riesgos y la exposición, como la reprogramación de citas y el aplazamiento de trasplantes. Conclusión: las intervenciones realizadas fueron eficientes y están de acuerdo con las recomendaciones de los organismos nacionales e internacionales, sin embargo, la vigilancia constante es una necesidad.

Descriptores: Trasplante de Células Madre Hematopoyéticas. Trasplante de Médula Ósea. Infecciones por Coronavirus. Virus del SARS. Cuidados de Enfermería.

\section{Introdução}

Desde o surgimento e início das notificações dos primeiros casos do Severe Acute Respiratory Syndrome Coronavirus 2 (SARS-CoV-2), em dezembro de 2019, na cidade de Wuhan, na China, várias evidências epidemiológicas e clínicas são apresentadas para auxiliar na construção da história natural desta doença. A rápida evolução para uma pandemia trouxe uma série de ameaças à ordem global, fazendo com que estratégias de enfrentamento fossem desenvolvidas em carácter emergencial ${ }^{(1)}$.

A organização dos serviços de saúde e a gestão para o enfrentamento e controle da infecção necessitaram ser realizadas com o desenvolvimento de medidas efetivas adotadas global e localmente ${ }^{(1)}$. Nesse cenário de tensão, reorganização dos serviços de saúde e mudança de hábitos, o medo da contaminação e das consequências da Coronavirus disease 2019 (COVID-19), possivelmente, causou sofrimentos aos pacientes acometidos por alguma patologia ${ }^{(2)}$.

Os pacientes que necessitam de transplante de células-tronco hematopoéticas (TCTH) compõem uma população vulnerável, devido à doença de base e à imunossupressão causadas por tratamentos prévios, para os quais a infecção por SARS-CoV-2 parece causar consequências trágicas e até fatais ${ }^{(3)}$. Ao considerar a especificidade do TCTH, sociedades científicas nacionais e internacionais dedicadas à área têm publicado orientações e protocolos de cuidado com base em documentos emitidos pela Organização Mundial da Saúde (OMS) ${ }^{(4)}$ e por pesquisas desenvolvidas por estudiosos da área do $\mathrm{TCTH}^{(5-7)}$. Essas 
publicações apoiam os profissionais de saúde com atualizações que fundamentam o estabelecimento de novas rotinas e treinamentos, equipe, pacientes e familiares, com vistas a evitar ou retardar a propagação da doença, promovendo maior segurança ao paciente, que enfrenta além de um diagnóstico que ameaça a vida, o medo de uma doença desconhecida.

Para a população geral, as medidas de contenção globalmente utilizadas são: higienização das mãos, uso de máscara, isolamento social, detecção de casos suspeitos e tratamento dos casos $\operatorname{confirmados}^{(8)}$. No entanto, no contexto da população de transplantados, que apresenta maior risco de desfecho desfavorável, além desses cuidados, existe a necessidade da adoção de normas, rotinas e protocolos com vistas à especificidade da área, como reorganização do fluxo de internamentos para o TCTH e a priorização de pacientes sem condições clínicas de espera.

Entende-se que esse manejo é fundamental para a identificação e prevenção de contaminação pelo SARS-CoV-2, e que as medidas podem sofrer adaptações de acordo com as características institucionais, disponibilidade de recursos e especificidades dos pacientes. Desse modo, surgiu a questão norteadora do presente estudo: Quais as implicações que a pandemia COVID-19 ocasionou no Serviço de Transplante de Células-Tronco Hematopoéticas? Para respondê-la, esta pesquisa teve como objetivo descrever as principais mudanças que a pandemia COVID-19 ocasionou na rotina de um serviço de referência na América Latina para Transplante de Células-Tronco Hematopoéticas.

\section{Método}

Trata-se de estudo observacional, transversal, realizado em um Serviço de Transplante de Medula Óssea (STMO) de um hospital universitário no sul do Brasil, referência na América Latina ${ }^{(9)}$. O serviço possui o setor ambulatorial onde são realizados os atendimentos pré-transplante e a assistência continuada aos pacientes transplantados (follow-up); e os setores internação e Hospital Dia onde ocorrem a realização do transplante, o atendimento pós-TCTH imediato até a pega medular e o atendimento das possíveis intercorrências.

A coleta de dados ocorreu de março a outubro de 2020 no setor ambulatorial e internação do STMO, na vigência da pandemia COVID-19, com o auxílio de instrumento de coleta de dados construído pela autora principal. Os dados referentes às ações de cuidados adotadas pelo STMO para controle da infecção por SARS-CoV-2 foram coletados por consulta documental, em rotinas descritas em manuais de procedimento operacional padrão, protocolos e fluxos do serviço, tais como: fluxo de entrada e isolamento dos casos suspeitos e confirmados e registros de treinamentos realizados no período.

As informações relacionadas aos atendimentos de pacientes foram coletadas por consulta em prontuários físicos e eletrônicos. As variáveis coletadas foram: número de transplantes, modalidade, quantitativo de transplantes adiados em virtude da pandemia e número de exames realizados para pesquisa de vírus respiratórios em pacientes sintomáticos. As informações relacionadas à equipe de saúde foram coletadas por consulta documental no STMO. As variáveis coletadas foram: índice de profissionais contaminados e afastados por COVID-19.

As ações de cuidados que foram realizadas pelo STMO foram comparadas com os protocolos de atendimento e cuidado, desenvolvidos por instituições internacionais - European Society for Blood and Marrow Transplantation (EBMT) ${ }^{(10-11)}$, American Society of Clinical Oncology (ASCO) ${ }^{(12)}$ e American Society for Transplantation and Cellular Therapy $\left(\right.$ ASTCT) ${ }^{(13)}$ - e com as recomendações da Agência Nacional de Vigilância Sanitária (ANVISA) ${ }^{(8)}$, e as diretrizes das instituições da área - Sociedade Brasileira de Transplante de Medula Óssea $(\text { SBTMO })^{(14)}$ e Associação Brasileira de Hematologia, Hemoterapia e Terapia Celular $(\mathrm{ABHH})^{(15)}$.

Para a análise comparativa das ações de cuidados para controle da infecção por SARS-CoV-2 desenvolvidas no STMO e as recomendadas pelas instituições especialistas na 
temática, foram realizadas leituras dos protocolos, das diretrizes e recomendações de atendimento e cuidado.

As variáveis obtidas foram tabuladas em planilha do Microsoft Excel 2010®. Posteriormente foi realizada a análise descritiva, com os resultados expressos em frequências simples, absolutas e relativas.

Este estudo é parte integrante do projeto temático "Análise das Ações de Cuidados aos Transplantados de Células-Tronco Hematopoéticas e Seus Familiares na Pandemia COVID-19" com aprovação pelo Comitê de Ética em Pesquisa (CEP), Parecer n. 4.290.200.

\section{Resultados}

Com relação a casuística referente aos dados dos pacientes, observa-se na Tabela 1 que foram realizados 60 TCTH, 53 (88\%) TCTH alogênicos e os demais TCTH autólogos. O TCTH alogênico aparentado teve como fonte de células-tronco mais prevalente a medula óssea (MO) fresca (sem congelamento prévio). Em relação à quantidade de transplantes adiados devido à pandemia, 22 (36,67\%) procedimentos foram suspensos. Destes, 16 (26,67\%) ainda não haviam sido realizados até a data final da coleta de dados, outubro de 2020.

Tabela 1- Caracterização dos transplante de células-tronco hematopoéticas alogênicos, fonte de células tronco-hematopoéticas e modalidade de infusão dos transplantes. Curitiba, Paraná, Brasil, mar.-out. 2020

\begin{tabular}{|c|c|c|c|c|c|}
\hline \multicolumn{2}{|l|}{ TCTH (1) } & \multicolumn{2}{|c|}{ CTH (2) } & \multicolumn{2}{|c|}{ Infusão dos transplantes } \\
\hline Tipo & n (\%) & Fonte & n (\%) & Modalidade & n (\%) \\
\hline \multirow{4}{*}{$\begin{array}{l}\text { Alogênico Não } \\
\text { Aparentado }\end{array}$} & $17(28 \%)$ & Medula Óssea & $12(20 \%)$ & Fresca & $4(7 \%)$ \\
\hline & & & & Criopreservada/descongelada & $8(13 \%)$ \\
\hline & & Sangue Periférico & $5(8 \%)$ & Fresco & $2(3 \%)$ \\
\hline & & & & Criopreservado/descongelado & $3(8 \%)$ \\
\hline \multirow{4}{*}{$\begin{array}{l}\text { Alogênico } \\
\text { Aparentado }\end{array}$} & $36(60 \%)$ & Medula Óssea & $29(48 \%)$ & Fresca & $27(45 \%)$ \\
\hline & & & & Criopreservada/descongelada & $2(3 \%)$ \\
\hline & & Sangue Periférico & $7(12 \%)$ & Fresco & $6(10 \%)$ \\
\hline & & & & Criopreservado/descongelado & $1(2 \%)$ \\
\hline
\end{tabular}

Fonte: Elaboração Própria.

(1) TCTH - Transplante de células-tronco hematopoéticas.

(2) CTH - Células tronco-hematopoéticas.

Quanto aos sintomas apresentados pelos pacientes, das 137 internações, 25 (41,67\%) indivíduos em pós-transplante apresentaram febre ou sintomas respiratórios e tiveram exames coletados para Vírus Respiratórios Múltiplos (VRMULT) e SARS CoV-2, totalizando 55 exames. Destes, 53 (96\%) foram negativos para a COVID-19. Os dois (4\%) pacientes que positivaram foram atendidos no Hospital-Dia. O primeiro apresentou sintomas respiratórios leves e foi mantido em atenção ambulatorial. O segundo necessitou de reinternação por sintomas respiratórios e neutropenia, porém apresentou piora progressiva com necessidade de transferência para a Unidade de Terapia Intensiva (UTI). Este apresentou testes negativos para a COVID-19 na admissão da UTI e positivou dez dias após a transferência.
Na etapa pré-TCTH, fase realizada no ambulatório do TMO na vigência da pandemia, todos os pacientes foram testados com a realização do RT-PCR para SARS-CoV-2 antes da internação e/ou antes de iniciar o condicionamento. Pacientes em pós-TCTH passaram por ações mais rigorosas de prevenção e controle e foram conduzidos para avaliações, caso a caso.

$\mathrm{Na}$ fase pós-TCTH, os pacientes que recebem alta hospitalar permanecem em seguimento ambulatorial ou em atendimento no Hospital Dia com uma rotina assistencial até aproximadamente três meses após o transplante. Durante a pandemia, com o objetivo de reduzir os deslocamentos dos pacientes e sua permanência no STMO e diminuir a exposição e o risco de contaminação, foram adotadas, entre outras condutas, 
a redução da frequência de realização de coletas de exames laboratoriais, adaptações quanto ao uso de medicações intravenosas substituídas para via oral, altas ambulatoriais antecipadas.

Cuidados específicos também foram adotados em relação aos doadores, que além de igualmente serem testados para SARS-CoV-2, para maior segurança do receptor, foram realizadas avaliações da história clínica e epidemiológica, com classificação de risco. Todos os resultados dos 60 pacientes pré-transplante e dos 36 doadores recebidos na unidade foram negativos.

No que se refere aos profissionais de saúde, houve a coleta de exames para detectar a presença da infecção pela COVID-19 em duas situações: em toda a equipe, na segunda quinzena de abril, com o objetivo de rastrear casos assintomáticos; nos casos em que os profissionais apresentavam sintomas, como coriza, tosse e febre. Durante a etapa de coleta de dados, dos 72 profissionais, 8 testaram positivos ( 4 enfermeiros, 3 médicos e 1 técnico de enfermagem), o que representa $11 \%$ da força de trabalho do serviço. Nesse sentido, foi necessária a reestruturação da escala dos profissionais para atendimento dos casos suspeitos ou de pacientes que aguardavam resultados, para evitar exposição desnecessária durante a assistência nos quartos de isolamento respiratório.

Ademais, o Serviço de Controle de Infecção Hospitalar (SCIH) disponibilizou treinamentos com vídeos com orientações sobre paramentação e desparamentação, bem como atualizações e cursos na modalidade à distância. Para aqueles que necessitaram de afastamento de suas atividades durante o período da pandemia, foi disponibilizado atendimento virtual com a Unidade de Saúde e Segurança do Trabalhador (SOST).

Para a análise comparativa das ações de cuidados recomendadas pelas instituições nacionais e internacionais e as adotadas no STMO para a prevenção da doença causada pelo SARS-CoV2, o Quadro 1 apresenta separadamente as ações implementadas/recomendadas ao centro de TCTH, aos doadores, aos pacientes durante o pré-transplante, internação e pós-transplante, aos profissionais de saúde e também as não implementadas.

Quadro 1 - Principais ações implementadas/não implementadas no serviço TCTH para combate da COVID-19

\begin{tabular}{|c|c|c|}
\hline Destinatários & Recomendações implementadas & $\begin{array}{c}\text { Recomendações não } \\
\text { implementadas }\end{array}$ \\
\hline $\begin{array}{l}\text { Centros } \\
\text { transplantadores }\end{array}$ & $\begin{array}{l}\text { Reorganização do fluxo de entrada de pacientes no } \\
\text { serviço de transplante. } \\
\text { Instruções quanto ao distanciamento entre pacientes. } \\
\text { Reagendamento de consultas médicas não urgentes. } \\
\text { Isolamento dos pacientes que aguardam resultado de } \\
\text { exame para SARS-CoV-2. } \\
\text { Separação das equipes para atendimento a pacientes } \\
\text { com COVID-19. } \\
\text { Disponibilização de Equipamentos de proteção } \\
\text { individual (EPIs) para menor exposição à COVID-19. } \\
\text { Restrição de visitas o máximo possível. } \\
\text { Orientação quanto às coletas, sempre que possível, com } \\
\text { o uso de sangue periférico como fonte de CT e enxerto } \\
\text { criopreservado. }\end{array}$ & $\begin{array}{l}\text { Disponibilização } \\
\text { de consultas por } \\
\text { telemedicina. }\end{array}$ \\
\hline Receptores & $\begin{array}{l}\text { Avaliação do Risco x Benefício para suspensão dos } \\
\text { transplantes sempre que as condições clínicas do } \\
\text { receptor permitirem. } \\
\text { Orientacão quanto à necessidade de isolamento } \\
\text { domiciliar, higiene das mãos, por, pelo menos, } 14 \text { dias } \\
\text { antes do início do condicionamento. } \\
\text { Testagem por RT-PCR para SARS-CoV-2 na pré-admissão. }\end{array}$ & \\
\hline
\end{tabular}


Quadro 1 - Principais ações implementadas/não implementadas no serviço TCTH para combate da COVID-19

\begin{tabular}{|c|c|c|}
\hline Destinatários & Recomendações implementadas & $\begin{array}{c}\text { Recomendações não } \\
\text { implementadas }\end{array}$ \\
\hline $\begin{array}{l}\text { Pacientes } \\
\text { transplantados }\end{array}$ & $\begin{array}{l}\text { Intensificação do monitoramento de reações adversas, } \\
\text { incluindo os sinais e sintomas clássicos e respiratórios } \\
\text { da infecção por SARS-CoV-2. } \\
\text { Preparo do paciente para alta hospitalar durante toda a } \\
\text { internação. } \\
\text { Alta precoce sempre que as condições clínicas do } \\
\text { paciente permitirem. }\end{array}$ & $\begin{array}{l}\text { Monitoramento de } \\
\text { sintomas mediante } \\
\text { contato telefônico. }\end{array}$ \\
\hline Doadores & $\begin{array}{l}\text { Avaliação do histórico epidemiológico quanto ao } \\
\text { contato com casos suspeitos ou confirmados de } \\
\text { SARS-CoV-2. } \\
\text { Testagem por RT-PCR para SARS-CoV-2, respeitando } \\
\text { a periodicidade dos exames de acordo com a } \\
\text { classificação de risco. }\end{array}$ & \\
\hline $\begin{array}{l}\text { Profissionais de } \\
\text { saúde }\end{array}$ & $\begin{array}{l}\text { Testagem do profissional com sintoma respiratório ou } \\
\text { que teve contato com caso suspeito ou confirmado para } \\
\text { COVID-19. } \\
\text { Afastamento do profissional por } 14 \text { dias no caso } \\
\text { positivo para COVID-19, e nova testagem após esse } \\
\text { período. } \\
\text { Utilização de uniforme, visando a troca das roupas } \\
\text { externas para as internas do hospital. } \\
\text { Treinamento específico para paramentação e } \\
\text { desparamentação. } \\
\text { Atualização das rotinas e informações institucionais. }\end{array}$ & $\begin{array}{l}\text { Teste RT-PCR a todos } \\
\text { Os profissionais, } \\
\text { quando ocorre um caso } \\
\text { suspeito ou confirmado } \\
\text { dentro da unidade de } \\
\text { TCTH, para rastreio de } \\
\text { casos assintomáticos ou } \\
\text { pré-sintomáticos. }\end{array}$ \\
\hline
\end{tabular}

Fonte: Elaboração própria.

\section{Discussão}

O TCTH é uma modalidade terapêutica que traz esperança de cura e sobrevida, mas portam efeitos colaterais e inúmeros riscos aos pacientes. A presença da pandemia COVID-19 sobrecarregou a equipe multiprofissional e os pacientes com preocupações relacionadas à continuidade do tratamento dos pós-transplantados, a possibilidade de potencializar as complicações já esperadas, assim como a incerteza para recebimento do transplante.

Observa-se que não houve redução expressiva de procedimentos quanto ao quantitativo de transplantes realizados durante o período de coleta de dados, tendo em vista que, no mesmo período do ano anterior, foram realizados 64 transplantes. Esse resultado revela que, embora tenha havido a reorganização do serviço em virtude da pandemia, os pacientes que estavam sendo acompanhados tiveram seus transplantes realizados. Em 2019 não houve uso de enxerto criopreservado para pacientes submetidos ao TCTH alogênico, entretanto, em 2020, foram 14 (23\%). Este dado converge com as recomendações do $\mathrm{EBMT}^{(10-11)}$ quanto aos procedimentos de criopreservação, representando um aumento em relação a essa prática.

Não foi possível observar, neste primeiro momento, as consequências da criopreservação. Alguns estudos sugerem perda da viabilidade das células após o descongelamento, comprometendo a qualidade do enxerto ${ }^{(16)}$ ou, por exemplo, aumento das reações ao dimetil sulfóxido (DMSO), principal substância utilizada no congelamento para garantir a viabilidade das células ${ }^{(16)}$. Esse acompanhamento deverá ser apresentado em estudos futuros.

Em relação à contaminação e letalidade da COVID-19 em receptores de TCTH, houve divergência com os resultados da pesquisa realizada na Espanha ${ }^{(17)}$, que apontou maior letalidade entre autólogos (24\%) do que em transplantes alogênicos (20\%). Na maior parte dos casos, os 
autólogos evoluem de forma mais complicada em relação à frequência de internações, admissão em UTI, ventilação mecânica, síndrome respiratória aguda grave (SRAG) e choque séptico; a provável causa dessas diferenças seria devido a maior mediana de idade em autólogos. No presente estudo, os dois pacientes que testaram positivos para COVID-19 realizaram transplante alogênico, sendo um com sintomas leves e o outro, com progressão dos sintomas e presença de outros complicadores relacionados ao TCTH.

O mesmo estudo espanhol ${ }^{(17)}$ apresenta que, nos casos de pacientes em pós-transplante com imunossupressão em curso, mucosite, desnutrição e/ou doença do enxerto contra hospedeiro (DECH), o risco de complicações pode aumentar se associado à infecção por COVID-19. No setor, houve monitoramento mais rigoroso de reações adversas nos pacientes transplantados com orientações contínuas desde a alta hospitalar. Destaca-se a importância das orientações junto ao paciente, em todas as fases do transplante, para o fortalecimento das medidas de prevenção, e do uso correto dos EPIs, pelos profissionais da saúde, para controle da infecção cruzada. Sem pormenorizar, apesar da vulnerabilidade desses pacientes à propagação e contaminação pelo SARS-CoV-2, somada à contaminação dos profissionais em condição assintomática, poucos foram os desfechos negativos, tendo em vista que 3,34\% dos pacientes foram contaminados.

Aos profissionais da saúde, em observância à Nota Técnica n. $4 / 2020^{(8)}$, foi reforçado o uso dos EPIs e a capacitação sobre o seu uso, além da higienização das mãos. Destaca-se que essa é uma prática diária no setor que se apresentou eficiente $^{(18)}$, pois mesmo com os profissionais positivos assintomáticos para COVID-19, não houve infecção cruzada. No entanto, trata-se de situação preocupante, pois não há recomendação de testagem periódica para os funcionários assintomáticos e estudos internacionais mostram que, em cada três infectados, um é assintomático ${ }^{(17,19-20)}$. O aumento de afastamento entre os profissionais acarreta a sobrecarga de trabalho na equipe, gerando impacto psicológico, como fadiga e aumento do estresse, expondo ainda mais os trabalhadores da "linha de frente" e evidenciando as demandas históricas do setor saúde ${ }^{(21-22)}$.

Nesse cenário, é preciso destacar a importância que os profissionais de saúde tiveram no enfrentamento da pandemia, sendo imprescindíveis na manutenção de toda a assistência prestada. As medidas implementadas minimizaram os impactos da COVID-19 e impactaram na prevenção da disseminação do vírus ${ }^{(23)}$, principalmente, ao considerarmos a complexidade e a vulnerabilidade do paciente no contexto do TCTH e dos casos assintomáticos ${ }^{(24)}$.

De acordo com a Nota Técnica n. 36/2020 ${ }^{(19)}$, do Ministério da Saúde, o STMO seguiu as principais recomendações para doação e triagem clínica, com avaliação dos riscos e benefícios para a realização do transplante, elaboração de fluxo de entrada, isolamento para casos suspeitos e confirmados. As orientações e ações educativas para doadores, receptores de TCTH e familiares foram implementadas conforme as informações epidemiológicas e evidências científicas disponibilizadas pelas autoridades sanitárias nacionais e internacionais.

Com intuito de diminuir o volume de atendimento, os transplantes foram adiados sem risco para o paciente, medida relevante destacada por estudos $^{(14-15,19)}$. Em conformidade com a Nota Técnica n. 36/2020 ${ }^{(19)}$, do Ministério da Saúde, todos os pacientes em período pré-transplante foram testados para COVID-19 e ficaram em alas específicas enquanto aguardavam os resultados. Contudo, não houve no serviço o uso da telemedicina, sendo as consultas reagendadas conforme a condição clínica de cada paciente.

A presente publicação apresenta um conjunto de evidências relativas a uma visão geral do impacto da pandemia no STMO, apresentando a elaboração de planos estratégicos de preparação, planejamento e implementação das melhores práticas recomendadas ao combate e à disseminação da infecção. As limitações do estudo concentram-se na avaliação de um único centro transplantador e a realização de estudo transversal, o que dificulta a comparação e generalização dos resultados, bem como as análises não 
trazerem o número de consultas médicas reagendadas, tempo de internação e expansão das indicações de tratamentos com esquemas orais. Essas informações contribuiriam para avaliação pormenorizada das consequências da COVID-19 no setor em estudo.

\section{Conclusão}

Diversas ações foram implementadas, incluindo intervenções nos centros transplantadores, cuidados com os receptores, pacientes transplantados, doadores e condutas com os profissionais de saúde, de forma a reduzir as possibilidades de contaminação dos pacientes e da equipe de saúde. As intervenções realizadas mostraram-se eficientes e estão de acordo com as recomendações de órgãos nacionais e internacionais, no entanto, a constante vigilância é uma necessidade.

O número de transplantes realizados foi similar ao mesmo período do ano anterior, revelando que, embora o serviço tenha se reorganizado, o quantitativo de procedimentos não sofreu influência da pandemia. Evidencia-se, também, a referência do serviço no atendimento a pacientes críticos com necessidade de tratamento de urgência.

Embora a vacinação contra a COVID-19 esteja em curso, a principal estratégia de prevenção da disseminação continua sendo evitar a exposição ao SARS-CoV-2. Espera-se que o estudo contribua com a organização dos serviços mediante ações para mitigação e auxílio nos processos de cuidado em situações de emergência.

\section{Colaborações:}

1 - concepção, projeto, análise e interpretação dos dados: Natália Naome Oshiro;

2 - redação do artigo, revisão crítica relevante do conteúdo intelectual: Natália Naome Oshiro, Luciana de Alcantara Nogueira, Luana Aparecida Alves da Silva e Teresinha Keiko Kojo;

3 - aprovação final da versão a ser publicada: Celina Angélica Mattos Machado e Luciana Puchalski Kalinke.

\section{Agradecimentos}

À equipe do Transplante de Medula Óssea do Complexo Hospitalar de Clínicas da Universidade Federal do Paraná pela colaboração com este estudo e pela competência e dedicação dedicados ao cuidado dos pacientes.

\section{Referências}

1. Brasil. Ministério da Saúde. Secretaria de Vigilância em Saúde. Plano de Contingência Nacional para Infecção Humana pelo novo Coronavírus COVID-19 [Internet]. Brasília (DF); 2020 [cited 2020 Dec 29]. Available from: https:// portalarquivos2.saude.gov.br/images/pdf/2020/ fevereiro/13/plano-contingencia-coronavirusCOVID19.pdf

2. Cirilo SSV, Silva PHS, Cruz VT, Correia RS, Maia JPC, Silva FBF. Necessidade de Assistência Psicossocial em Tempos de Pandemia Causada pelo Novo Coronavírus: um Olhar Atento aos Pacientes Oncológicos e aos Profissionais da Área da Oncologia. Rev Bras Cancerol. 2020;66(TemaAtual):e-1071. DOI: https://doi.org/ 10.32635/2176-9745.RBC.2020v66nTemaAtual.1071

3. Willan J, King AJ, Hayes S, Collins GP, Peniket A. Care of haematology patients in a COVID-19 epidemic. Br J Haematol. 2020;189(2):241-3. DOI:10.1111/bjh.16620

4. World Health Organization. COVID-19 Strategic Preparedness and Response Plan Operational Planning Guidelines [Internet]. Geneva (CH); 2020. [cited 2021 Jan 10]. Available from: https:// www.who.int/publications/m/item/covid-19strategic-preparedness-and-response-planoperational-planning-guideline

5. Duarte FB, Lemes RPG, Duarte IA, Duarte BA, Duarte JVA. Hematological changes in Covid-19 infections. Rev Assoc Med Bras. 2020;66(2):5 DOI: https://doi.org/10.1590/1806-9282.66.2.99

6. Golchin A, Seyedjafari E, Ardeshirylajimi A. Mesenchymal Stem Cell Therapy for COVID-19: Present or Future. Stem Cell Rev and Rep. 2020;16(3):427-33. DOI: https://doi.org/10.1007/ s12015-020-09973-W

7. Szer J, Weisdorf D, Querol S, Foeken L, Madrigal L. The impact of COVID-19 on the provision of donor hematopoietic stem cell products worldwide: collateral damage. Bone 
Marrow Transplant. 2020;55(10):2043-4. DOI: https://doi.org/10.1038/s41409-020-0873-x

8. Agência Nacional de Vigilância Sanitária. Nota Técnica no 4, de 31 de março de 2020. Orientações para serviços de saúde: medidas de prevenção e controle que devem ser adotadas durante a assistência aos casos suspeitos ou confirmados de infecção pelo novo coronavírus (SARS-CoV-2) [Internet]. Brasília (DF); 2020 [cited 2020 Dec 29]. Available from: http://portal. anvisa.gov.br/documents/33852/271858/Nota+T \%C3\%A9cnica+n+042020+GVIMSGGTES-ANVISA/ ab598660-3de4-4f14-8e6f-b9341c196b28

9. Picchioni EA, Souza FOF, Camargo KAV, Sonvessi LA, Rodrigues MLF. Transplante de Medula Óssea no Complexo Hospital de Clínicas da Universidade Federal do Paraná: pioneirismo, inovação e excelência. Rev Multidisciplinar em Saúde. 2021;2(1):5. DOI: https://doi.org/10.51161/ rems.616

10. European Society for Blood and Marrow Transplantation. Coronavirus Disease COVID-19: EBMT Recommendations. Version 13 [Internet] Barcelona (ES); 2020 [cited 2021 Jan 10]. Available from: https://www.ebmt.org/sites/ default/files/2020-12/EBMT\%20COVID-19\%20 guidelines $\% 20$ and $\% 20$ summary $\% 20$ v.13.pdf

11. European Society for Blood and Marrow Transplantation. Coronavirus Disease COVID-19: EBMT Recommendations. Version 16 [Internet]. Barcelona (ES); 2021 [cited 2021 Jun 10]. Available from: https://www.ebmt.org/sites/ default/files/2021-06/EBMT\%20COVID-19\%20 guidelines\%20v.\%2016.03.pdf

12. Pennell NA, Dillmon M, Levit LA, Moushey EA, Alva AS, Blau S, et al. American Society of Clinical Oncology Road to Recovery Report: Learning From the COVID-19 Experience to Improve Clinical Research and Cancer Care. J Clin Oncol. 2020;39(2):155-69. DOI: 10.1200/ JCO.20.02953

13. Zahra M, Maurice A, Julianna R, Ryan S, Terri LS, Colleen T, et al. American Society for Transplantation and Cellular Therapy Pharmacy Special Interest Group Position Statement on Pharmacy Practice Management and Clinical Management for COVID-19 in Hematopoietic Cell Transplantation and Cellular Therapy Patients in the United States. Biol Blood Marrow Transplant. 2020;26(6):1043-49. DOI: https://doi.org/10.1016/j. bbmt.2020.04.005
14. Sociedade Brasileira de Transplante de Medula Óssea. Recomendações para reduzir o risco de infecção pelo vírus "SARS CoV-2", no ambiente do transplante de células-tronco hematopoiéticas [Internet]. Rio de Janeiro; 2020 [cited 2020 Jan 5]. Available from: https://sbtmo.org.br/ kcfinder/upload/file/Recomenda\%C3\%A7\%C3\% B5es\%20para\%20Manejo\%20da\%20COVID\%20 10\%20dez\%202020.pdf

15. Associação Brasileira de Hematologia, Hemoterapia e Terapia Celular. Coletânea COVID-19 [Internet]. São Paulo; 2020 [cited 2020 Dec 29]. Available from: https://abhh.org.br/ institucional/coletanea-covid19/

16. Purtill D, Antonenas V, Chiappini P, Tong D, O'Flaherty E, Bajel A, et al. Variable CD34+ recovery of cryopreserved allogeneic HPC products: transplant implications during the COVID-19 pandemic. Blood Adv. 2020;4(17): 4147-50. DOI: 10.1182/bloodadvances. 2020002431

17. Coll E, Fernández-Ruiz M, Sánchez-Álvarez JE, Martínez-Fernández JR, Crespo M, Gayoso J, et al. COVID-19 in transplant recipients: The Spanish experience. Am J Transplant. 2021;21(5):1825-37. DOI: $10.1111 /$ ajt.16369

18. Rodrigues JAP, Stelmatchuk AM, Lacerda MR, Galvão CM. Covid-19 containment measures adopted in bone marrow transplantation service. Rev Bras Enferm. 2020;73(Suppl 2):e20200476. DOI: http://dx.doi.org/10.1590/0034-7167-20200476

19. Brasil. Ministério da Saúde. Secretaria de Atenção Especializada à Saúde. Nota Técnica no 36, de 22 de abril de 2020. Complementa as orientações da Nota Técnica № 25/2020-CGSNT/DAET/SAES/MS (0014073431) e suas atualizações, incluindo os critérios técnicos para o gerenciamento do risco sanitário de células-tronco hematopoécas (CTH) para fins de transplante convencional, e para o manejo de doadores e de receptores de $\mathrm{CTH}$ frente à pandemia de coronavírus (SARS-CoV-2) [Internet]. Brasília (DF); 2020 [cited 2020 Dec 2]. Available from: https://acreditacao.abhh.com.br/ adm/doc/ec1db83e7f8467bebfc2a0034952a537. pdf

20. Pollán M, Péres-Gómez B, Pastor-Barriuso R, Oteo J, Hernán M, Pérez-Olmeda $M$, et al. Prevalence of SARS-CoV-2 in Spain (ENE-COVID): a nationwide, population-based seroepidemiological study. Lancet. 2020;396(10250):535-44. DOI: 10.1016/S0140-6736(20)31483-5 
10

Implicações da Covid-19 num serviço de transplante de células-tronco hematopoéticas referência na América Latina

21. Anderson RM, Heesterbeek H, Klinkenberg D, Hollingsworth TD. How will country-based mitigation measures influence the course of the COVID-19epidemic. Lancet. 2020;395(10228):931-4. DOI: $10.1016 / \mathrm{S} 0140-6736(20) 30567-5$

22. Lai J, Ma S, Wang Y, Cai Z, Hu J, Wei N, et al. Factors Associated With Mental Health Outcomes Among Health Care Workers Exposed to Coronavirus Disease 2019. JAMA Netw Open. 2020;3(3):e203976. DOI: 10.1001/ jamanetworkopen.2020.3976

23. Santos KOB, Fernandes RDCP, Almeida MMC, Miranda SS, Mise YF, Lima MAG. (2020). Trabalho, saúde e vulnerabilidade na pandemia de COVID-19. Cad Saúde Pública. 2020;36(12):e00178320. DOI: http://dx.doi.org/10.1590/0102-311x00178320

24. Albuquerque NLS. Planejamento operacional durante a pandemia de Covid-19: comparação entre recomendações da Organização Mundial da Saúde e o Plano de Contingência Nacional. Cogitare Enferm. 2020;25(72659):1-7. DOI: http:// dx.doi.org/10.5380/ce.v25i0.72659

Recebido: 2 de março de 2021

Aprovado: 21 de julho de 2021

Publicado: 20 de agosto de 2021

A Revista Baiana de Enfermagem utiliza a Licença Creative Commons - Atribuição-NãoComercial 4.0 Internacional.

https://creativecommons.org/licenses/by-nc/4.0/

Este artigo é de acesso aberto distribuído sob os termos da Licença Creative Commons (CC BY-NC).

Esta licença permite que outros remixem, adaptem e criem a partir do seu trabalho para fins não comerciais. Embora os novos trabalhos tenham de lhe atribuir o devido crédito e não possam ser usados para fins comerciais, os usuários não têm de licenciar esses trabalhos derivados sob os mesmos termos. 